\title{
Minocycline-induced hyperpigmentation: comparison of 3 Q-switched lasers to reverse its effects
}

This article was published in the following Dove Press journal:

Clinical, Cosmetic and Investigational Dermatology

30 May 2013

Number of times this article has been viewed

\author{
Mahrukh S Nisar' \\ Karthik lyer' \\ Robert T Brodell ${ }^{2}$ \\ Jenifer R Lloyd ${ }^{3}$ \\ Thuzar M Shin ${ }^{3}$ \\ Asad Ahmad ${ }^{4}$
}

'Northeast Ohio Medical University, Rootstown, OH, USA; 'Division of Dermatology, University of Mississippi Medical Center, Jackson, MS, USA; ${ }^{3}$ Case Western Reserve University School of Medicine, Cleveland, OH, USA: ${ }^{4}$ Northside Medical Center. Youngstown, OH, USA
Correspondence: Jenifer R Lloyd Case Western Reserve University School of Medicine, 10900 Euclid Avenue, Cleveland, OH, USA

Tel +I 3307589189

Fax +l 3307584487

Email jr12@neomed.edu
Abstract: Minocycline is a tetracycline derivative antibiotic commonly prescribed for acne, rosacea, and other inflammatory skin disorders. Minocycline turns black when oxidized, leading to discoloration of the skin, nails, bulbar conjunctiva, oral mucosa, teeth, bones, and thyroid gland. Hyperpigmentation has been reported after long-term minocycline therapy with at least $100 \mathrm{mg} /$ day. Three types of minocycline-induced cutaneous hyperpigmentation can result. Type $\mathrm{I}$ is the most common, and is associated with blue-black discoloration in areas of previous inflammation and scarring. Type II most commonly affects the legs and is characterized by blue-gray pigmentation of previously normal skin. Type III is the least common and is characterized by diffuse muddy-brown discoloration predominantly on sun exposed skin. Minocycline-induced hyperpigmentation may be cosmetically disfiguring and prompt identification is essential. Without treatment, symptoms may take several months, to years to resolve, after discontinuation of the drug. However, the pigmentation may never completely disappear. In fact, there have been few reports of complete resolution associated with any therapeutic intervention. We report a case of a patient on long-term minocycline therapy utilized as an anti-inflammatory agent to control symptoms of rheumatoid arthritis, which led to minocycline-induced hyperpigmentation of the face. To remove the blue-gray cutaneous deposits, 3 Q-switched lasers (Neodymium: yttrium aluminum garnet (Nd:YAG) $1064 \mathrm{~nm}$, Alexandrite $755 \mathrm{~nm}$, and Ruby $694 \mathrm{~nm}$ ) were used in test areas. The Alexandrite $755 \mathrm{~nm}$ laser proved to provide effective clearing of the minocycline hyperpigmentation requiring just 2 treatments, with minimal treatment discomfort and down time.

Keywords: rheumatoid arthritis, discoloration, antibiotic, inflammatory disease, tetracycline, wavelength

\section{Introduction}

Diffuse blue-gray skin discoloration has been reported in several conditions such as Addison's disease, argyria, hemochromatosis and polycythemia vera. ${ }^{1}$ Riehl melanosis is characterized by brown-violet pigmentation on sun-exposed areas, erythema, and pruritus. ${ }^{2}$ Erythema dyschromicum perstans is either idiopathic or acquired, typically occurs in those younger than 40 years, and first presents with erythematous macules that slowly turn slate gray resulting in gray-blue hypermelanosis. ${ }^{2}$ Finally, end-stage metastatic melanoma can produce a blue-gray to brown hue to the body. ${ }^{2}$ In addition, drugs including minocycline, amiodarone, zidovudine, and bleomycin have been reported to cause cutaneous darkening (Table 1).

Minocycline is a semi-synthetic tetracycline antibiotic that turns black when oxidized, and can produce discoloration of the skin, nails, oral mucosa, conjunctiva, 
Table I Drugs associated with cutaneous darkening and special attributes

\begin{tabular}{|c|c|}
\hline Drug & Description \\
\hline \multirow[t]{3}{*}{ Minocycline $e^{12}$} & Type I: blue-grey pigmentation of normal skin \\
\hline & Type II: blue-black pigmentation of inflamed/scarred skin \\
\hline & Type III: muddy brown pigmentation with sun-exposure \\
\hline Amiodarone ${ }^{13}$ & $\begin{array}{l}\text { Slate-colored, blue-gray to purple discoloration of sun- } \\
\text { exposed skin }\end{array}$ \\
\hline Bleomycin $^{14}$ & $\begin{array}{l}\text { Dark brown flagellate (band-like) hyperpigmentation } \\
\text { on areas of trauma, especially trunk and proximal } \\
\text { extremities }\end{array}$ \\
\hline Zidovudine $^{15}$ & $\begin{array}{l}\text { Melanonychia and mucosal hyperpigmentation (more } \\
\text { common in dark-skinned individuals) }\end{array}$ \\
\hline
\end{tabular}

teeth, bones, and thyroid gland. ${ }^{3}$ Three types of minocycline-induced cutaneous hyperpigmentation have been described: ${ }^{3}$

- Type I is the most common, and is associated with blueblack discoloration in areas of previous inflammation and scarring.

- Type II most commonly affects the legs and is characterized by blue-gray pigmentation of previously normal skin.

- Type III is the least common and is characterized by diffuse muddy-brown discoloration predominantly on sun-exposed skin.

Minocycline-induced hyperpigmentation is associated with long-term use of this drug. Any patient receiving more than 100 grams of minocycline can develop discoloration. ${ }^{4}$ The pigment deposition is the result of a drug metaboliteprotein complex chelated with calcium, or an insoluble minocycline-melanin complex. ${ }^{5}$ Minocycline hyperpigmentation occurs in $2.4 \%$ to $14.8 \%$ of patients on chronic treatment, most commonly for acne and rosacea. ${ }^{5}$ In a study of 700 patients on high-dose long-term minocycline treatment for acne (100 mg daily, 100/200 mg on alternate days, or $200 \mathrm{mg}$ daily for 10.5 months), the only side effect that was significantly greater in patients taking higher doses (cumulative dose greater than $70 \mathrm{~g}$ ) compared with lower doses was pigmentation $(P<0.01){ }^{6}$ Its anti-inflammatory effects are helpful for rheumatoid arthritis, immunobullous disease and other inflammatory diseases. ${ }^{3}$ The incidence of minocycline pigmentation is higher in patients treated for autoimmune diseases and may be more common with increasing age. ${ }^{3}$

Q-switched lasers use high energy, nanosecond pulsing and are available in 3 wavelengths for drug-induced pigmentation, including the Ruby $694 \mathrm{~nm}$, the Alexandrite $755 \mathrm{~nm}$, and the Nd:YAG infrared $1064 \mathrm{~nm} .{ }^{7}$ There have been reports of the Alexandrite laser leading to the resolution of Type II minocycline induced hyperpigmentation. ${ }^{6}$ Other reports have shown efficacy of the Ruby laser for minocycline facial and leg pigmentation. ${ }^{8,9}$ A single study compared the YAG and Ruby lasers in the treatment of minocycline pigmentation and the Ruby laser was found to be more effective. ${ }^{9}$ However, there are no studies comparing the 3 Q-switched lasers for effectiveness and patient comfort in the treatment of minocycline-induced hyperpigmentation.

\section{Case}

A 70-year-old caucasian male presented with a one-year history of progressive worsening blue-gray discoloration of the face. There were no associated symptoms and no history of previous gold therapy. Physical examination revealed macular, non-blanching, diffuse blue-gray hyperpigmentation on the forehead, temples, cheeks, nose, and chin sparing the oral mucosa. The patient was taking $100 \mathrm{mg}$ of minocycline orally twice daily for 3 years (total 219 grams) to suppress symptoms of rheumatoid arthritis. The patient noticed increased darkening of the face over the past year. Minocycline was discontinued to prevent further pigmentation. A $0.4 \times 0.3 \times 0.3 \mathrm{~cm}$ punch biopsy demonstrated mild perivascular lymphocytic infiltrates with increased pigment deposition in the basal layers of the epidermis (Figure 1). Iron stain was negative (Figure 2).

The patient was spot-treated with 3 Q-switched lasers (1064 nm, [Palomar Spectrum RD1200] 755 nm, and $694 \mathrm{~nm}$ [both Syneron-Candela Alex Trivantage]) to evaluate which laser would achieve the best results in removing pigmentation with minimal discomfort. No topical anesthetic was used. The

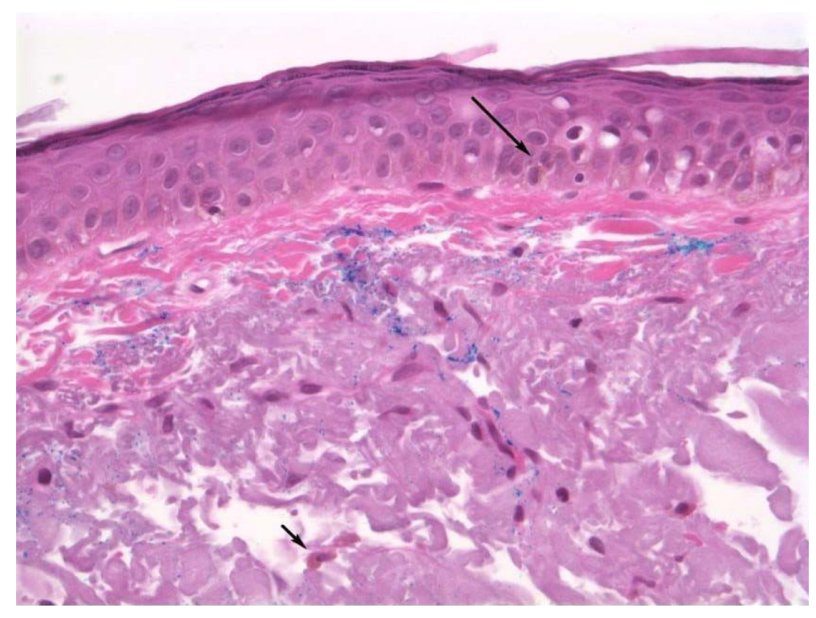

Figure I Minocycline-induced hyperpigmentation.

Notes: There is increased faintly visible light brown pigment (melanin) within the basal keratinocytes (long arrow) and dermal dendocytes (short arrow). The blue pigment within the papillary dermis is the ink used for margins. 


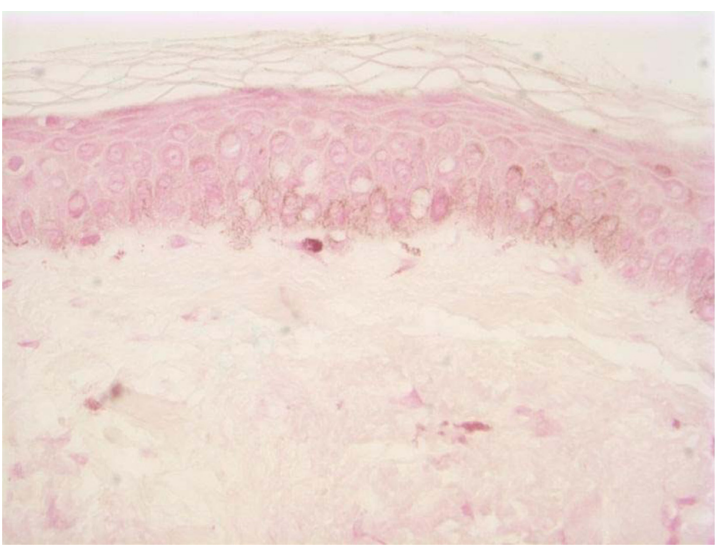

Figure 2 Iron stain.

Notes: This high power view shoes the pigment within the basal keratinocytes and dermal macrophages is negative for iron. the pigment is slightly better visualized here than routine hematoxyline and eosin in Figure $\mathrm{I}$.

$1064 \mathrm{~nm}$ laser was set at 1.6 joules ( $\mathrm{J})$ with a $5 \mathrm{~mm}$ spot size. The $755 \mathrm{~nm}$ laser used a fluence of $5.5 \mathrm{~J}$ with a $4 \mathrm{~mm}$ spot size. The $694 \mathrm{~nm}$ was set at $4 \mathrm{~J}$ with a $6.5 \mathrm{~mm}$ spot size. The results of the trial therapy after 1 week are shown in Figure 3. The $1064 \mathrm{~nm}$ revealed minimal to no change in pigment. The $755 \mathrm{~nm}$ showed a 50\% improvement with minimal discomfort. The $694 \mathrm{~nm}$ showed 90\% improvement, however was uncomfortable for the patient. We chose the $755 \mathrm{~nm}$ laser for treatment based on its significant improvement with minimal pain, discomfort, and downtime for the patient. The patient received two full-face treatments spaced 2 weeks apart with the $755 \mathrm{~nm}$ at $5.5 \mathrm{~J}$ and $4 \mathrm{~mm}$ spot size and one follow-up spot treatment. These treatments led to complete resolution of hyperpigmentation and the patient was completely satisfied with the result (Figure 4). Sun protection was encouraged following treatments.

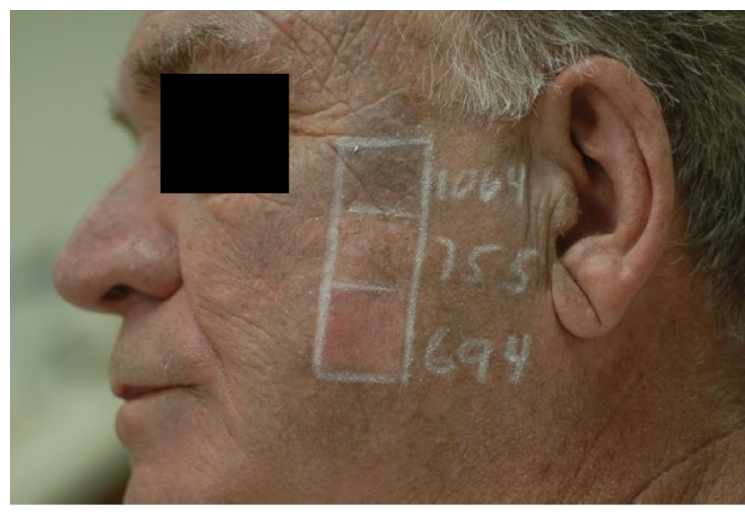

Figure 3 Diffuse blue-black darkening after prolonged minocycline use. Notes: Spot-treatment trialed with 3 Q-switched lasers (Neodynium: YAG 1064 nm, Alexandrite 755 nm, and Ruby 694 nm).

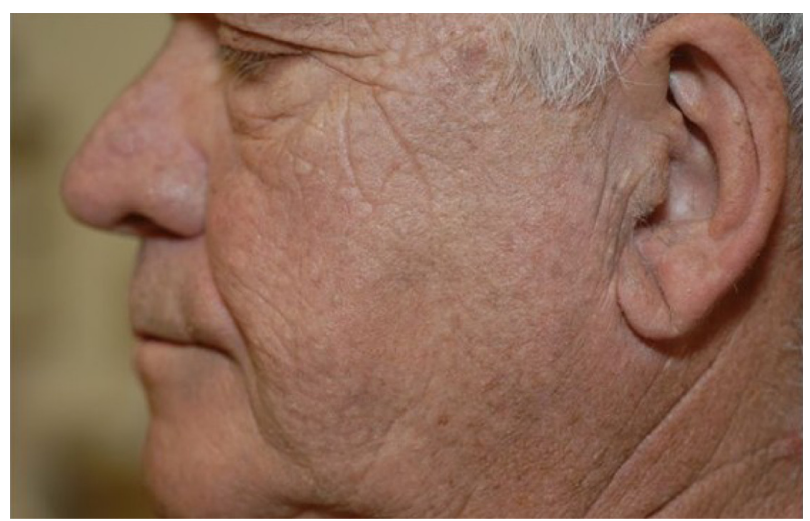

Figure 4 Results after 2 sessions with the Q-switched Alexandrite $(755 \mathrm{~nm})$ laser.

\section{Discussion}

This patient had Type III minocycline-induced hyperpigmentation on the sun-exposed skin of the face after taking 219 grams of minocycline over 3 years. Of the 3 Q-switched lasers tested, the $755 \mathrm{~nm}$ laser was effective in reversing pigmentation with minimal patient discomfort after 2 treatments. Type III minocycline-induced hyperpigmentation is less likely to respond than Types I and II. ${ }^{3}$ It is not known exactly how laser therapy removes the pigment associated with minocycline use, but is thought to result from fragmentation of the intracellular and extracellular pigmentation and drainage through the lymphatic system. ${ }^{2}$

The recommended minocycline dose for acne is $100-200$ $\mathrm{mg}$ daily. Many patients treated for a year or two will reach a cumulative dose of over $100 \mathrm{~g}$. According to the US Food and Drug Administration (FDA), there is a manufacturing delay of tetracycline leading to a shortage of the drug. ${ }^{10}$ As a result, physicians are forced to use alternative medications such as doxycycline. ${ }^{10}$ Therefore, we may see a greater incidence of minocycline-induced hyperpigmentation as minocycline prescribing increases. Fortunately, we can utilize the Alexandrite $755 \mathrm{~nm}$ laser to remove pigmentation associated with the use of this drug. A recent case reported successful treatment with the Alexandrite laser, with the patient deciding to continue minocycline therapy and returning 3 years later with recurrence to receive another laser treatment. ${ }^{11}$

\section{Disclosure}

The authors report no conflicts of interest in this work.

\section{References}

1. Merchant F, Carpenter T. Blue-gray discoloration of the skin. Am Fam Physician. October 1, 2011;84(7):821-8222.

2. Kalia S, Adams SP. Dermcase. Minocycline-induced pigmentation. Can Family Physician. May 2006;52:595-596. 
3. Pecina JL, Pittelkow MR. Hyperpigmentation - a case study. Aust Fam Physician. Sep 2011;40(9):701-702.

4. Eisen D, Hakim MD. Minocycline-induced pigmentation: Incidence, prevention, and management. Drug Saf. Jun 1998;18(6): 431-440.

5. Mouton RW, Jordaan HF, Schneider JW. A new type of minocyclineinduced cutaneous hyperpigmentation. Clin Exp Dermatol. Jan 2004; 29(1):8-14.

6. Green D, Friedman KJ. Treatment of minocycline-induced cutaneous pigmentation with the Q-switched Alexandrite laser and a review of the literature. J Am Acad Dermatol. Feb 2001;44(Suppl 2):342-347.

7. Goulden V, Glass D, Cunliffe WJ. Safety of long-term high-dose minocycline in the treatment of acne. Br J Dermatol. Apr 1996;134(4):693-695.

8. Knoell KA, Milgraum SS, Kutenplon M. Q-switched ruby laser treatment of minocycline-induced cutaneous hyperpigmentation. Arch Dermatol. Oct 1996;132(10):1251-1253.

9. Tsao H, Busam K, Barnhill RL, Dover JS. Treatment of minocyclineinduced hyperpigmentation with the Q-switched ruby laser. Arch Dermatol. Oct 1996;132(10):1250-1251.
10. Ruth C. Running on empty. FDA, Congress working to mitigate drug shortages. Derm World. Jul 2012.

11. Samalonis LB. Q-switched lasers effective for treating drug-induced hyperpigmentation. Dermatology Times. March 1, 2012.

12. Holm AN, Nelson WK. Images in clinical medicine. Minocycline-induced hyperpigmentation. N Engl J Med. November 16, 2006;355(20):e23.

13. Wiper A, Roberts DH, Schmitt M. Amiodarone-induced skin pigmentation: Q-switched laser therapy, an effective treatment option. Heart. Jan 2007;93(1):15.

14. Gupta LK, Tanwar RK, Khare AK, Jain SK. Bleomycin induced flagellate pigmentation. Indian J Dermatol Venereol Leprol. May-Jun 2002; 68(3): 158-159.

15. Greenberg RG, Berger TG. Nail and mucocutaneous hyperpigmentation with azidothymidine therapy. J Am Acad Dermatol. Feb 1990; 22(2 Pt 2):327-330.
Clinical, Cosmetic and Investigational Dermatology

\section{Publish your work in this journal}

Clinical, Cosmetic and Investigational Dermatology is an international, peer-reviewed, open access, online journal that focuses on the latest clinical and experimental research in all aspects of skin disease and cosmetic interventions. All areas of dermatology will be covered; contributions will be welcomed from all clinicians and

\section{Dovepress}

basic science researchers globally. This journal is indexed on CAS The manuscript management system is completely online and includes a very quick and fair peer-review system, which is all easy to use. Visit http://www.dovepress.com/testimonials.php to read real quotes from published authors. 